\title{
Involved Surgical Margin Indicator
}

National Cancer Institute

\section{Source}

National Cancer Institute. Involved Surgical Margin Indicator. NCI Thesaurus. Code C93581.

Specifies whether the margins of surgical resection are infiltrated by disease. 